\title{
Pathways to psychiatric care in Eastern Europe
}

RICHARD GATER, VESNA JORDANOVA, NADJA MARIC, VALBONA ALIKAJ, MAJA BAJS, TAMARA CAVIC, HRISTO DIMITROV, DIANA IOSUB, ADRIANA MIHAI, ANDREEA SILVANA SZALONTAY, HANFRIED HELMCHEN and NORMAN SARTORIUS

\begin{abstract}
Background There has been almost no research into mental health services in Eastern Europe. A pathways study is a quick and useful starting point, requiring few resources.
\end{abstract}

\begin{abstract}
Aims To improve understanding of prior care-seeking and treatment of new patients seen at mental health services.
\end{abstract}

Method Pathways diagrams were drawn showing the routes of care-seeking for 50 new patients in eight centres. Patterns of care-seeking, durations and previous treatments were compared for ICD-10 diagnostic groups.

Results The diagnoses varied according to the organisation of services. Major pathways included general practitioners, direct access and hospital doctors.

General practitioners have a limited role as 'gatekeeper' in centres in Albania, Croatia, Macedonia, Romania and SerbiaMontenegro, and rarely prescribed treatment, except sedatives, for mental disorders

Conclusions Findings highlight areas that require attention if aspirations for community-oriented mental health care are to be realised, particularly integration of mental health into primary care.

Declaration of interest None.
The Eastern European Psychiatric Scientific Initiative (E-EPSI) group is a recently formed group of psychiatrists who are aiming to obtain information about mental health services in Central and Eastern Europe and make suggestions concerning their improvement. The first project of the E-EPSI is a study of pathways to care. An understanding of the way people seek care for mental disorders is increasingly recognised as important for planning mental health services, provision of appropriate training and referral from other sectors of health and social care. Pathway studies have been used to investigate the roles of previous carers and time on the pathway (Gater et al, 1991; Vázquez-Barquero et al, 1993; Kilic et al, 1994; Gureje et al, 1995; Patel et al, 1997; Razali \& Najib, 2000; Linden et $a l, 2003$ ) and to monitor the effects of service developments over time (Harrison et al, 1997; Amaddeo et $a l, 2001)$.

\section{METHOD}

A collaborative study of the pathways that lead to psychiatric services was carried out in eight centres: Belgrade in SerbiaMontenegro, Bucharest, Iasi and Tg. Mures in Romania, Sofia in Bulgaria, Strumica in Macedonia, Tirana in Albania and Zagreb in Croatia, using the methodology of the World Health Organization Study of Pathways to Care (Gater et al, 1991). Taking account of feasibility issues in the participating centres and previous experience using the pathways method, a sample size of 50 was estimated to be sufficient for a meaningful analysis. All those that were newly referred to the psychiatric services and agreed to participate were interviewed until the target 50 participants were recruited in each centre. Newly referred patients were defined as those who had not sought care from the mental health service during the previous year. There were no exclusion criteria. The fieldwork was carried out between February and May 2003.

Those eligible were interviewed using an encounter form, which was previously used in a study coordinated by the World Health Organization (Gater et al, 1991). The form gathers information on sociodemographic characteristics of participants and sources of care before reaching the mental health service. The encounter form was translated into Albanian, Bulgarian, Croatian, Macedonian, Romanian and Serbian. The psychiatrist in charge completed the questionnaire, which took 5-10 min. An instruction and coding manual was supplied to each psychiatrist who took part in the fieldwork.

The routes taken by participants from each centre were combined in a 'pathways diagram'. The proportion taking each route was marked on the pathways diagram. The time intervals between onset of problem, first seeking care and arrival at the mental health services were compared between centres and diagnostic groups. Comparisons according to individual diagnostic groups were made by groups of centres with sufficiently large numbers of cases. Diagnostic groups were based on ICD-10 categories (World Health Organization, 1992): mental and behavioural syndromes associated with psychoactive substance misuse (F10-19), schizophrenia, schizotypal and delusional disorders (F20-29), mood disorders (F30-39) and neurotic, stress-related and somatoform disorders (F40-49). Schizophrenia, schizotypal and delusional disorders were further divided into schizophrenia or schizoaffective disorder (F20 and F25) and other psychotic disorders. Other diagnoses did not occur in sufficient numbers for meaningful analysis. Categorical data were analysed using the $\chi^{2}$-test. Continuous variables (such as duration of problem) were highly skewed; therefore average values are presented as medians; analysis employed Kruskal-Wallis analysis of variance.

\section{Participating centres}

The participating centres share a number of important characteristics. All are in transition from predominantly institutional to community-based care, but at present the mental health services are almost entirely hospital based. Although in most centres primary care is widely distributed and accessible, general practice has yet to 
Table I Previous history, current diagnosis, and patients who suggested seeking care at each centre

\begin{tabular}{|c|c|c|c|c|c|c|c|c|}
\hline \multirow[t]{2}{*}{ Centre } & \multicolumn{6}{|c|}{ ICD-I0 diagnostic group 9} & \multirow{2}{*}{$\begin{array}{c}\text { Previous } \\
\text { psychiatric } \\
\text { history } \\
n(\%)\end{array}$} & \multirow{2}{*}{$\begin{array}{c}\text { Patient } \\
\text { suggested } \\
\text { seeking care } \\
n(\%)\end{array}$} \\
\hline & $\begin{array}{c}\text { Schizophrenia' } \\
n(\%)\end{array}$ & $\begin{array}{c}\text { Other } \\
\text { psychotic } \\
\text { disorders }{ }^{2} \\
n(\%)\end{array}$ & $\begin{array}{c}\text { Mood } \\
\text { disorder } \\
n(\%)\end{array}$ & $\begin{array}{c}\text { Neurotic } \\
\text { disorder } \\
n(\%)\end{array}$ & $\begin{array}{c}\text { Substance } \\
\text { misuse }^{4} \\
n(\%)\end{array}$ & $\begin{array}{l}\text { Other mental } \\
\text { disorder } \\
n(\%)\end{array}$ & & \\
\hline Bucharest & $13(26)$ & $6(12)$ & $7(14)$ & $2(4)$ & $12(24)$ & $10\left(20^{6}\right)$ & $16(38)$ & $16(32)$ \\
\hline lasi & $15(30)$ & II (22) & $12(24)$ & $0(0)$ & $8(16)$ & $4(8)$ & $32(64)$ & $8(16)$ \\
\hline Sofia & I (2) & $2(4)$ & $19(38)$ & $21(42)$ & I (2) & $6\left(12^{6}\right)$ & $18(36)$ & $21(42)$ \\
\hline Strumica & $15(30)$ & $12(24)$ & $10(20)$ & $5(10)$ & I (2) & $7\left(14^{7}\right)$ & $19(38)$ & $16(32)$ \\
\hline Turgu Mures & $2(4)$ & $5(10)$ & $13(26)$ & $12(24)$ & II (22) & $7\left(14^{8}\right)$ & $23(46)$ & $26(52)$ \\
\hline Tirana & $5(10)$ & $2(4)$ & $17(34)$ & $22(44)$ & $0(0)$ & $4(8)$ & $14(28)$ & $6(12)$ \\
\hline Combined & $66(16)$ & $60(15)$ & $94(23)$ & $93(23)$ & 42 (II) & $45(12)$ & $|5|$ & $139(35)$ \\
\hline
\end{tabular}

I. Schizophrenia and schizoaffective disorders.

2. All other diagnoses in the schizophrenia, schizotypal and delusional disorders group, excluding schizophrenia and schizoaffective disorders.

3. Neurotic, stress-related and somatoform disorders.

4. Mental and behavioural disorders due to psychoactive substance misuse.

5. Participating psychiatrists in Belgrade usually do not diagnose schizophrenia in new patients until a short period of observation has been completed.

6. In Bucharest and Sofia, $12 \%$ had an organic mental disorder.

7. In Strumica, $8 \%$ had behavioural syndromes associated with physiological disturbances and physical factors.

8. In Tirgu Mures, $8 \%$ had learning disabilities.

9. World Health Organization, 1992.

establish its place in mental healthcare. Communications between general practitioners and psychiatrists are rare at an individual, institutional and guild (professional society) level. In most countries involved, regulations require that a psychiatrist recommends an antidepressant before the general practitioner can prescribe; there are a limited number of psychotropic medications on the 'positive' list (available without charge), whereas others on the 'negative' list have to be paid for.

In Belgrade, where there are about ten psychiatrists per 100000 population, participants were recruited at a large general psychiatric hospital. This is a state institution and all costs of treatment are covered by regular insurance. In Bucharest individuals were seen in the emergency and outpatient wards of the largest general psychiatric hospital in Romania. There are about 8.3 psychiatrists per 100000 population and all public psychiatric services are covered by the regular medical insurance. Those in Iasi were seen in the University Hospital of Psychiatry, which is a state institution where costs are covered by insurance. There are 8.5 psychiatrists per 100000 population. The service in Sofia is a private medical centre, replacing a former polyclinic (community primary and secondary care clinic), which receives donations from the local municipality and state. There are four psychiatrists per 100000 population. Since this psychiatric service was only recently established, a substantial number of those with severe mental illness continue to receive psychiatric services elsewhere. In Strumica, an out-patient clinic and ward provide the only mental health service in the region, with 3.3 psychiatrists per 100000 population. These are state institutions and the National Health Insurance Fund covers treatment costs. At the University Psychiatric Clinic of Tirgu Mures costs of treatment are covered by regular insurance. There are 5.4 psychiatrists per 100000 population. In Tirana, participants were seen at the University Clinic of Psychiatry. There are 1.2 psychiatrists per 100000 population. In Zagreb, the study was carried out in the emergency service of a large general psychiatric hospital. This is a state institution where national insurance covers admission and treatment costs, and there are about ten psychiatrists per 100000 population.

\section{RESULTS}

At each centre, data were collected from 50 new patients seen as new out-patients, emergency assessments or new patients referred for admission. There were no refusals in any of the centres. The samples in all eight centres included approximately $60 \%$ women, but in other respects the demographic profile differed between centres. The mean age was 40 years, with an older average age in Sofia ( 50 years) and younger age in Belgrade, Iasi, Strumica and Tirana (33-36 years). In Sofia and Tirana, twothirds of the participants were married and living together, or cohabiting, whereas those in Belgrade, Bucharest, Iasi and Strumica were usually single. In Bucharest, Strumica and Zagreb the majority of participants were rated of below average social class, whereas only a minority were so rated in Belgrade.

The most frequent diagnoses in all centres combined were mood and neurotic disorders (23\% each), followed by schizophrenia $(16 \%)$, other psychotic disorders $(15 \%)$ and mental disorders due to substance misuse $(11 \%)$. However, this distribution does not reflect the situation in any of the individual centres, which varied significantly $(P<0.001)$ (Table 1$)$. These differences are most likely to reflect differences in the mental health services and should not be interpreted as differences in the prevalence of mental illness. Between 28 and $38 \%$ of new patients from most centres had a previous psychiatric history but higher rates were found in Iasi $(64 \%)$ and Tirgu Mures (46\%) $(P<0.01)$. 


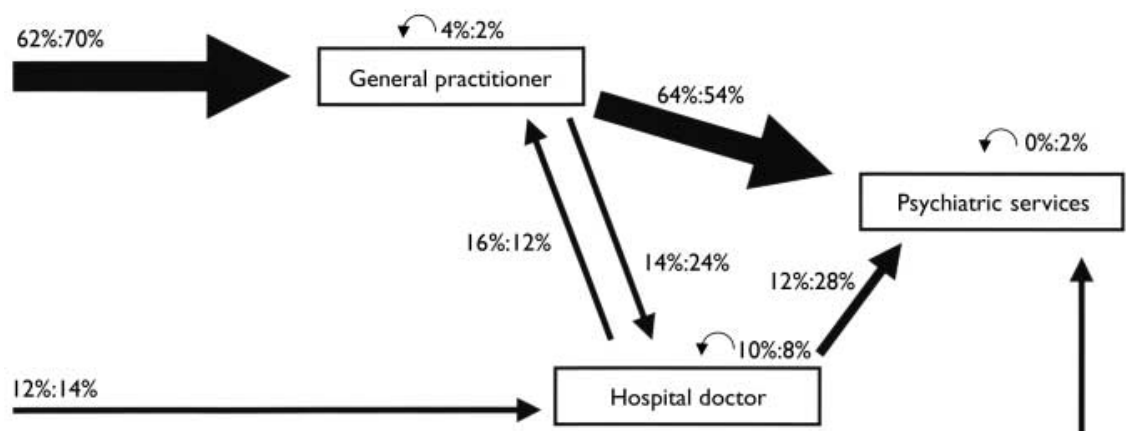

$16 \%: 14 \%$

Fig. I Pathways to psychiatric care in Sofia and Tirgu Mures. Percentage of those taking each step in Sofia and Tirgu Mures respectively for carers involved in more than $5 \%$ of pathways. (Curved arrows above carer boxes indicate recursive pathways, where patients have gone from one to another of the same type of carer.)

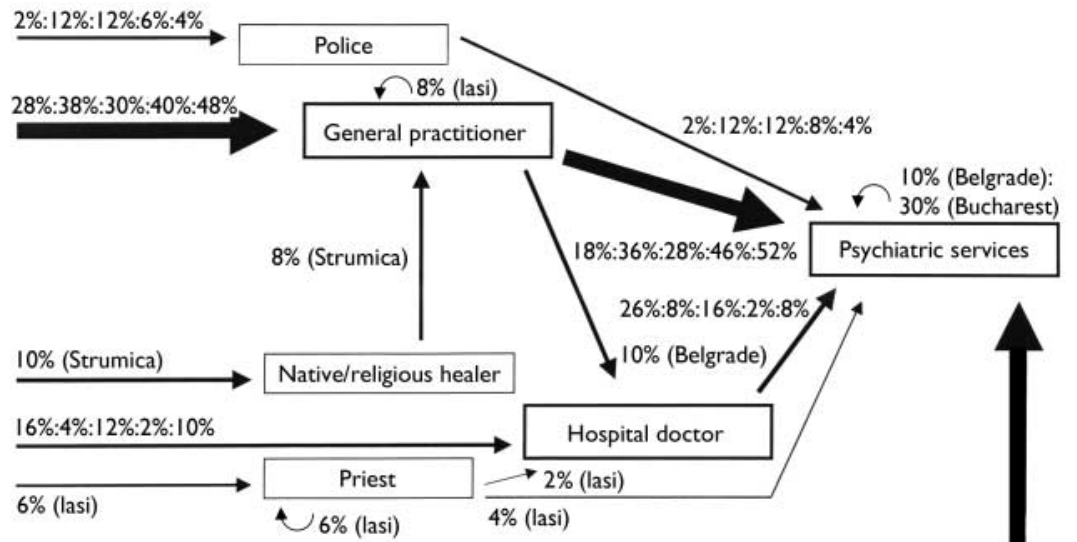

$37 \%: 46 \%: 32 \% 38 \%: 36 \%$

Fig. 2 Pathways to psychiatric care in Belgrade, Bucharest, lasi, Strumica and Zagreb. Percentage of those taking each step for each centre respectively, for carers involved in more than $5 \%$ of pathways. Steps occurring in only one or two centres are indicated as a single figure followed by the centre name in brackets. (Curved arrows above carer boxes indicate recursive pathways, where patients have gone from one to another of the same type of carer.)

The suggestion to first seek care most often came from family or friends for those initially presenting with psychotic symptoms $(70 \%)$, violent, aggressive or other disturbed behaviour $(100 \%)$ and attempted suicide $(90 \%)$. Family members first suggested psychiatric care more frequently than either previous carers or individuals themselves for all diagnostic groups.

In all centres combined, $87 \%$ first sought care from a doctor, usually a general practitioner $(40 \%)$ or by directly accessing centres with a substantial flow between general practitioners and hospital doctors.

General practitioners played a substantial but less prominent role in Belgrade, Bucharest, Iasi, Strumica and Zagreb (Fig. 2). In contrast to Sofia and Tirgu Mures, individuals in these five centres made more frequent use of direct access to psychiatric services $(32-46 \%)$. Within this group there are some notable variations, such as the low use of hospital doctors in Bucharest and Strumica, the involvement of the police in $12 \%$ of cases in Bucharest and Iasi, native or religious healers in $10 \%$ in Strumica and priests in $6 \%$ in Iasi; $10 \%$ of patients in Belgrade and $30 \%$ of those in Bucharest had seen another psychiatrist before they arrived at the study psychiatric service.

Entry to psychiatric care in Tirana is almost exclusively through hospital doctors and direct access, with a few patients arriving via community/specialist nurses and native or religious healers (Fig. 3). General practitioners are not shown in Fig. 3 because they were involved with only $2 \%$ of participants.

Subsequent results are based on the ICD-10 diagnostic groups, with data presented for those centres with the largest numbers in the relevant groups. In all centres combined, more than half of those with schizophrenia made direct contact with psychiatric services and less than a quarter first sought care from a general practitioner (Table 2). Direct access was less frequent among those with other disorders. More participants with schizophrenia had a previous psychiatric history than those with other diagnoses, but previous history was not significantly associated with choice of first carer and did not account for the greater use of direct access among those with schizophrenia.

First carers varied between centres for schizophrenia $(P=0.001)$, mood disorder $(P<0.01)$ and neurotic disorder $(P<0.01)$. More than two-thirds of those with schizophrenia in Bucharest and Strumica went directly to the psychiatric services compared with about half of those in Iasi and Zagreb. In Zagreb half of those with schizophrenia first went to a general practitioner compared with only $10 \%$ in Iasi and Strumica. Police were the first source of care for $15 \%$ of those with schizophrenia in Iasi and $13 \%$ in Strumica.

Those with mood or neurotic disorders often visited general practitioners first in 


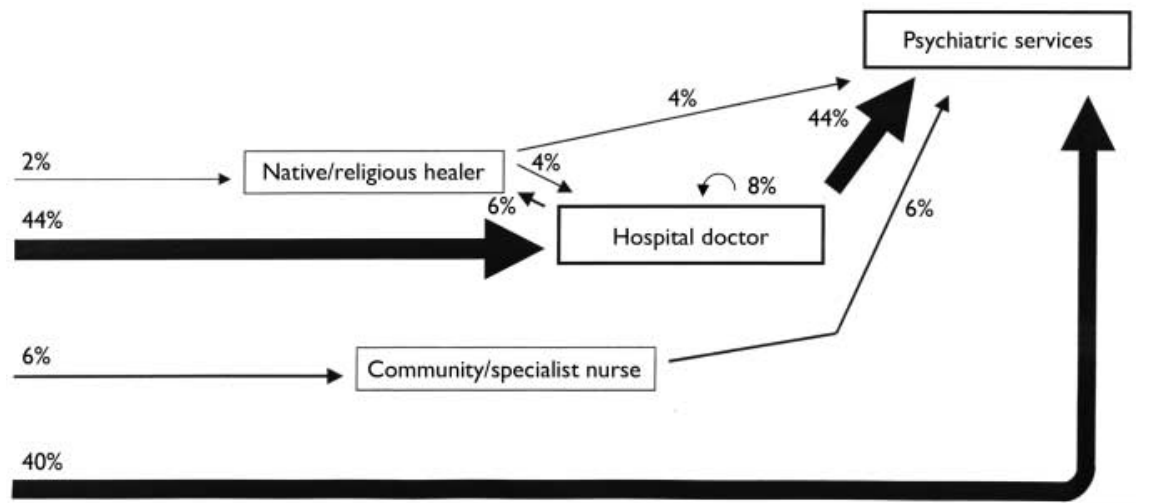

Fig. 3 Pathways to psychiatric care in Tirana. Percentage of those taking each step for carers involved in more than $5 \%$ of pathways. (Curved arrows above carer boxes indicate recursive pathways, where patients have gone from one to another of the same type of carer.)

Belgrade and Sofia, whereas in Tirana the most frequent first carers were hospital doctors or the psychiatric services. Police were rarely involved with those with mood or neurotic disorders.
In all centres combined, the median total durations of time from the onset of main problem to arrival at the psychiatric service were shorter for those with schizophrenia and other psychotic disorders compared with neurotic disorders and substance misuse $(P<0.001)$ (Table 3$)$. For individual diagnostic groups, the total duration of problems did not differ significantly between centres. There were significant differences between centres for duration before seeking care for those with other psychotic disorders $(P<0.05$; shortest durations in Zagreb and Bucharest) and for mood disorders $(P<0.05$; shortest durations in Iasi and Strumica).

The median time between first seeking care and arrival at the psychiatric services was 3 weeks or less for all diagnoses. Those who had seen a general practitioner or hospital doctor were typically referred to the psychiatric services within a median of 2 or 3 weeks. In Belgrade there was a tendency towards a longer median duration after seeing a general practitioner (6 weeks) but this was not statistically significant.

The most common initial presenting problems to the first carer were psychotic

Table 2 Number of first carers according to diagnosis and centre (for centres with largest numbers in the diagnostic group)

\begin{tabular}{|c|c|c|c|c|c|}
\hline & \multirow{2}{*}{$\begin{array}{c}\text { New patients } \\
\text { with the diagnosis } \\
n\end{array}$} & \multicolumn{4}{|c|}{ New patients who first sought care from each type of carer } \\
\hline & & $\begin{array}{c}\text { General practitioner } \\
n(\%)\end{array}$ & $\begin{array}{c}\text { Hospital doctor } \\
n(\%)\end{array}$ & $\begin{array}{l}\text { Police } \\
n(\%)\end{array}$ & $\begin{array}{c}\text { Psychiatric services } \\
n(\%)\end{array}$ \\
\hline \multicolumn{6}{|l|}{ Schizophrenia } \\
\hline Bucharest & 13 & $3(23)$ & $0(0)$ & I (8) & $9(69)$ \\
\hline lasi & 13 & I (8) & I (8) & $2(15)$ & $7(54)$ \\
\hline Strumica & 15 & $2(13)$ & $0(0)$ & $2(13)$ & $10(67)$ \\
\hline Zagreb & 15 & $7(47)$ & $0(0)$ & $0(0)$ & $7(47)$ \\
\hline All centres combined & 64 & $14(22)$ & $3(5)$ & $5(8)$ & $36(56)$ \\
\hline \multicolumn{6}{|l|}{ Other psychotic disorders } \\
\hline Belgrade & 14 & $3(2 I)$ & $0(0)$ & I (7) & $6(43)$ \\
\hline lasi & II & $5(46)$ & I (9) & I (9) & $2(18)$ \\
\hline Strumica & 12 & $6(50)$ & $0(0)$ & $0(0)$ & $4(33)$ \\
\hline All centres combined & 60 & $26(43)$ & $3(5)$ & $5(8)$ & $18(30)$ \\
\hline \multicolumn{6}{|l|}{ Mood disorder } \\
\hline Sofia & 19 & $13(68)$ & I (5) & $0(0)$ & $4(2 I)$ \\
\hline Tirana & 17 & I (6) & $6(35)$ & I (6) & $6(35)$ \\
\hline All centres combined & 93 & $40(43)$ & $15(16)$ & $2(2)$ & $28(30)$ \\
\hline \multicolumn{6}{|l|}{ Neurotic disorder } \\
\hline Belgrade & 23 & II (48) & $4(17)$ & $0(0)$ & $6(26)$ \\
\hline Sofia & 21 & II (52) & $4(19)$ & $0(0)$ & $3(14)$ \\
\hline Tirana & 22 & $0(0)$ & $10(46)$ & $0(0)$ & $10(46)$ \\
\hline All centres combined & 93 & $39(42)$ & $23(25)$ & $0(0)$ & $24(26)$ \\
\hline \multicolumn{6}{|l|}{ Substance misuse } \\
\hline Bucharest & 12 & $4(33)$ & I (8) & I (8) & $6(50)$ \\
\hline Tirgu Mures & II & $6(55)$ & I (9) & $0(0)$ & $3(27)$ \\
\hline All centres combined & 42 & $16(38)$ & $3(7)$ & $4(10)$ & $18(43)$ \\
\hline
\end{tabular}


Table 3 Durations (weeks) on the pathway to care according to centres and diagnostic groups

\begin{tabular}{|c|c|c|c|c|c|}
\hline & $\begin{array}{l}\text { Duration of main } \\
\text { problem } \\
\text { Median } \\
\text { (interquartile range) }\end{array}$ & $\begin{array}{l}\text { Time from onset } \\
\text { of problem to first } \\
\text { seeking care } \\
\text { Median } \\
\text { (interquartile range) }\end{array}$ & $\begin{array}{l}\text { Time from first seeking } \\
\text { care to arrival } \\
\text { at psychiatric services } \\
\text { Median } \\
\text { (interquartile range) }\end{array}$ & $\begin{array}{c}\text { Time from first } \\
\text { seeking care from GP } \\
\text { to arrival at psychiatric } \\
\text { services' } \\
\text { Median } \\
\text { (interquartile range) }\end{array}$ & $\begin{array}{c}\text { Time from first seeking } \\
\text { care from hospital doctor } \\
\text { to arrival at psychiatric } \\
\text { services' } \\
\text { Median } \\
\text { (interquartile range) }\end{array}$ \\
\hline \multicolumn{6}{|l|}{ Schizophrenia } \\
\hline Bucharest & $3(1-11)$ & $3(I-I I)$ & $0(0-1)$ & - & - \\
\hline lasi & $5.5(2-11)$ & $2.5(I-8)$ & $0(0-3)$ & - & - \\
\hline Strumica & $6(1-10)$ & $4(\mathrm{I}-8)$ & $0(0-2)$ & - & - \\
\hline Zagreb & $5(3-6)$ & $2(0-3)$ & $3(3-4)$ & - & - \\
\hline All centres combined & $5(2-8)$ & $2(1-6)$ & $0(0-3)$ & $2(I-4)$ & $2(0-48)$ \\
\hline \multicolumn{6}{|c|}{ Other psychotic disorders } \\
\hline Belgrade & $8(4-24)$ & $3.5(0-18)$ & $0.5(0-4)$ & - & - \\
\hline lasi & $4(2-8)$ & $3(I-4)$ & $2(0-5)$ & - & - \\
\hline Strumica & $6.5(4-9)$ & $4(2-7)$ & $2(0-5)$ & - & - \\
\hline All centres combined & $6(3-11)$ & $3(0-5)$ & $2(0-4)$ & $2(1-6)$ & $3(0-4)$ \\
\hline \multicolumn{6}{|l|}{ Mood disorder } \\
\hline Sofia & $12(8-34)$ & $10(4-12)$ & $2(0-3)$ & $2(0-3)$ & - \\
\hline Tirana & $8(2-16)$ & $4(1-12)$ & $0(0-I)$ & - & - \\
\hline All centres combined & $7.5(3-15)$ & $4(2-12)$ & I (0-3) & $2(I-6)$ & $2(0-5)$ \\
\hline \multicolumn{6}{|l|}{ Neurotic disorders } \\
\hline Belgrade & $24(8-28)$ & $18(3-24)$ & $2(0-6)$ & $6(4-24)$ & - \\
\hline Sofia & $20(4-44)$ & $4(2-26)$ & $3(0-14)$ & $3(0-4)$ & - \\
\hline Tirana & $8(3-26)$ & $4(1-19)$ & $0(0-1)$ & - & - \\
\hline All centres combined & $14(4-27)$ & $4(1-19)$ & I (0-6) & $4(I-I I)$ & $3(1-12)$ \\
\hline \multicolumn{6}{|l|}{ Substance misuse } \\
\hline Bucharest & $80(0-202)$ & $80(0-20 I)$ & $0(0-0)$ & - & - \\
\hline Tirgu Mures & $4(0-52)$ & $4(0-52)$ & $0(0-1)$ & - & - \\
\hline All centres combined & $9(I-56)$ & $7(\mathrm{I}-55)$ & $0(0-I)$ & I (0-2) & $0(0-0)$ \\
\hline
\end{tabular}

I. No data presented for centres with counts of 12 or less.

(24\%), depressive $(19 \%)$, somatic $(17 \%)$ and anxiety $(12 \%)$ symptoms. This pattern had changed by the time individuals presented to the mental health services, with a greater proportion of psychotic $(31 \%)$ and fewer somatic $(10 \%)$ symptoms. Interpersonal problems and suicide attempts were infrequent at all centres (6\% or less).

In all centres combined, approximately half of the new patients had been offered a treatment by their general practitioner, most often a sedative or hypnotic. Those with schizophrenia or other psychotic disorders were more likely to have been offered a treatment by their general practitioner than those with other diagnoses. This treatment was most often an antipsychotic medication $(24 \%)$ or a sedative $(20 \%)$.
Nevertheless, $40 \%$ had not been offered any treatment by the general practitioner.

Mood, neurotic and substance misuserelated disorders had similar previous treatment profiles in all centres combined: over half had received no treatment from the general practitioner and $20-33 \%$ had been prescribed sedatives or hypnotics. Antidepressants were seldom prescribed to those with mood disorders $(5 \%)$ and neurotic disorders $(8 \%)$; they were prescribed almost equally to those with schizophrenia and other psychotic disorders $(4 \%)$.

\section{DISCUSSION}

This study was the first project of the newly formed E-EPSI group. It is the first serious scientific collaborative effort with these countries since the wars of the 1990s. The study was carried out with minimal resources, relying on the voluntary contributions of all concerned. The pathways study is not a comprehensive epidemiological investigation but can rapidly provide meaningful insights into the functioning of mental health services. This study has also consolidated the E-EPSI group and inspired future efforts to build an evidence base for the development of mental healthcare in Eastern Europe.

\section{Pathways}

The study has demonstrated that three models, determined by the extent to which 
general practitioners, hospital doctors and direct access are used, can represent pathways to psychiatric care in Eastern Europe. Direct access was the route for more than one-third of new patients in six centres. Irrespective of diagnosis, general practitioners played a limited role in the pathways to psychiatric care. A small proportion of patients consulted general practitioners; the only treatment provided by general practitioners was sedatives and hypnotics. Many factors contributed to this and included: lack of training and experience in psychiatry in primary care, absence of incentives, poor communications between the general practitioners and psychiatrists, availability of medication and regulations limiting the autonomy of general practitioners in managing mental disorders. If mental health is to be integrated into primary care, then an educational approach is more likely to succeed if this broader complex of factors is also addressed through the formal inclusion of mental health as a component of primary care and the further development and implementation of evidence-based national programmes for mental health. Factors limiting the integration of mental healthcare into general healthcare and interventions to overcome them have been described by Sartorius (1999).

\section{Family involvement}

Families and friends most often suggested seeking care, particularly if there were psychotic problems or behavioural disturbance with a risk to self or others. Families appear to be willing to help those with an illness but seek help when socially disturbing symptoms become prominent. If community mental healthcare is planned, then it will be important to realise the potential positive role of families through public education and partnership between mental health professionals and the families of people with mental illness.

\section{Variations between centres}

Organisational differences account for much of the variation in proportions of mental disorders between centres. The out-patient-based service in Sofia was established recently and most individuals with severe mental illness continue to attend the City State Psychiatric Dispensary; hence the low rates of schizophrenia and other psychotic disorders. In contrast, other centres such as Bucharest, Iasi and

\section{CLINICAL IMPLICATIONS}

Completion of this research marks a successful starting point for evidence-based mental healthcare in the region.

- In six centres, more than half of new patients made a direct approach to psychiatric services and general practitioners had a limited role as 'gatekeepers', indicating the need to review and change the system of care for the mentally ill.

- General practitioners had often provided no treatment for new patients arriving at psychiatric services; the most common treatments were sedatives or hypnotics; antidepressants were rarely prescribed, indicating the need for additional training of general practitioners.

\section{LIMITATIONS}

- The sample size is modest and limits the power of comparisons for diagnostic groups.

- Organisational differences between centres limits the direct comparison of all new patients between centres.

Self-reporting without confirmation from contemporary records may be subject to recall bias.

RICHARD GATER, MD, FRCPsych, University of Manchester and Lancashire Care NHS Trust, Preston, UK; VESNA JORDANOVA, MD, MSc, Institute of Psychiatry, Section of Epidemiology, London, UK; NADJA MARIC, MD, PhD, Medical School University of Belgrade, Institute of Psychiatry, Clinical Centre of Serbia, Belgrade, Serbia \& Montenegro; VALBONA ALIKAJ, MD, University Hospital Center "Mother Teresa", Clinic of Psychiatry, Tirana, Albania; MAJA BAJS, MD, University Hospital Dubrava, Department of Psychiatry, Zagreb, Croatia; TAMARA CAVIC, MD, PhD, Counselling Department, Institute for Neuropsychiatry "Dr Laza Lazarevic", Belgrade, Serbia \& Montenegro; HRISTO DIMITROV, MD, Psychiatric Department, University Hospital "Alexandrovska", Medical University Sofia, Sofia, Bulgaria; DIANA IOSUB, MD, Clinical Hospital of Psychiatry "Al. Obregia", Bucharest, Romania; ADRIANA MIHAI, MD, PhD, University of Medicine and Pharmacy, Tg. Mures, Romania; ANDREEA SILVANA SZALONTAY, MD, Department of Psychiatry and Health Psychology, University of Medicine and Pharmacy "Gr. T. Popa", lasi, Department of Psychiatry and Health Psychology, University Hospital of Psychiatry "Socola”, lasi, Romania; HANFRIED HELMCHEN, MD, Charite-University Medicine of Berlin, Psychiatric Department, Berlin, Germany; NORMAN SARTORIUS, MD, PhD, FRCPsych, Universities of Prague and Zagreb, and University of London, UK

Correspondence: Dr R. Gater, The Lantern Centre, off Watling Street Road, Fulwood, Preston PR2 8DY, UK. E-mail: richard.a.gater@manchester.ac.uk

(First received 18 May 2004, final revision 14 October 2004, accepted I8 October 2004)

Zagreb recruited new admissions to acute psychiatric wards with relatively high rates of schizophrenia and low rates of neurotic disorders. In Strumica, general practitioners are 'gatekeepers' for patients with neurotic disorders, and relatively few are referred to the psychiatrist; in Belgrade there are psychotherapeutic treatments available which attract such referrals. In the three Romanian centres there are no special units for alcohol dependence, which is treated in psychiatric hospitals. Primary care is not involved in care-seeking pathways in Tirana, and therefore the mental health service itself manages a relatively high proportion of patients with mood and neurotic disorders $(78 \%)$. The pathways in some centres included routes that reflect their individual circumstances. Native healers are popular in Strumica, particularly among the rural population. Bucharest retains six mental health laboratories from 
the communist period, and psychiatrists from these public institutions may refer to the study psychiatrists (hence the 30\% recursive pathways due to mental health laboratory psychiatrists as the previous carers). In the east of Romania, people are more religious and more often seek care from a priest, whereas in the west there is a mixture of cultures, including Romanian, Hungarian, German and Romas.

\section{Durations and previous treatment}

The time between first seeking care and arrival at mental health services for mood and neurotic disorders was generally short, so there was insufficient time for first-line treatments to be tried. General practitioners were more likely to prescribe sedatives or hypnotics than other treatments. Antidepressants were prescribed to very few participants and were almost as likely to be given to those with schizophrenia as those with depression. This pattern may arise in part from the constraints imposed by prescribing regulations and by the limitations imposed by the 'positive' list; there may also be reservations of both patients and doctors to the use of 'strong' medicines (such as antidepressants or antipsychotics), with connotations of severe mental illness, in favour of 'mild' medicines (such as sedatives or hypnotics), which are less taboo. These patterns of prescribing are not unique; they do not differ greatly from those reported from several centres in the original World Health Organization pathways study (Gater et al, 1991).

In Bucharest, the longer duration before first seeking care for substance misuse may be related to the increasing numbers of drug users, especially of a younger age. There is also a negative attitude towards illegal drug use, which the authorities consider to be a criminal issue, and this renders treatment services less likely to be available or used.

A key strength of this study was that it used the same methodology and standard encounter form in all centres. Trained and experienced psychiatrists completed the encounter forms and made diagnoses using the ICD-10 classification. However, diagnoses were not based on a standardised diagnostic interview and algorithm. The sample size of 50 participants per centre is modest, but sufficient to give a representation of pathways to care and some intercentre differences. The response rate was high in all centres, so minimising selection bias. Recall bias might have occurred as all information was based on self-report, and defining the onset of the main problem could be influenced by cultural factors, including the strong stigma associated with mental illness.

\section{Conclusions}

Although the sample and its size restrict the extent to which firm conclusions can be drawn from this study, there are clear indications for areas of further research. These include questions about the most effective and efficient target disorders for the specialist mental health services and the balance between hospital and community care. More apparent are questions about the role of primary care in mental healthcare in both the detection and management of mental disorders, and the barriers and solutions to incorporating mental health into primary care. The police and traditional healers could be trained to recognise mental illness in some centres.

The study has highlighted the important role of family and friends and suggests a significant impact of the stigma associated with mental disorders. These factors suggest the development of a public mental health approach and exploration of the best ways to collaborate with families. The pathways study has posed many questions, but if further progress is to be made there needs to be a shift to a more evidence-based culture and a reduction of the stigma associated with mental illness. We recommend that consideration be given to the inclusion of a research and development agenda in the national programmes of mental health.

\section{ACKNOWLEDGEMENTS}

We thank Dr Raina Popova (Sofia), llčo Šarlamanov (Strumica), and Ariel Çomo, Fatime Elezi and Lefter Sinani (Tirana), whose dedication made the study possible. The study was initiated during the attendance of the authors at the Berlin Summer School 2002 and supported by a grant from VolkswagenStiftung, Hannover.

\section{REFERENCES}

Amaddeo, F., Zambello, F., Tansella, M., et al (200I) Accessibility and pathways to psychiatric care in a community-based mental health system. Social Psychiatry and Psychiatric Epidemiology, 36, 500-507.

Gater, R., de Almeida e Sousa, B., Barrientos, G., et al (1991) The pathways to psychiatric care: a crosscultural study. Psychological Medicine, 2I, 76I-774.

Gureje, O., Acha, R. A. \& Odejide, O. A. (1995) Pathways to psychiatric care in Ibadan, Nigeria. Tropical and Geographical Medicine, 47, 125-129.

Harrison, J., Kisely, S. R., Jones, J. A., et al (1997) Access to psychiatric care; the results of the Pathways to Care study in Preston. Journal of Public Health Medicine, 19, 69-75.

Kilic, C., Rezaki, M., Ustün, T. B., et al (1994) Pathways to care in Ankara. Social Psychiatry and Psychiatric Epidemiology, 29, 131-136.

Linden, M., Gothe, H. \& Ormel, J. (2003) Pathways to care and psychological problems of general practice patients in a "gate keeper" and an "open access" health care system: a comparison of Germany and the Netherlands. Social Psychiatry and Psychiatric Epidemiology, 38, 690-697.

Patel, V., Simunyu, E. \& Gwanzura, F. (1997) The pathways to primary mental health care in high-density suburbs in Harare, Zimbabwe. Social Psychiatry and Psychiatric Epidemiology, 32, 97-103.

Razali, S. M. \& Najib, M. A. (2000) Help-seeking pathways among Malay psychiatric patients. International Journal of Social Psychiatry, 46, 28I-289.

Sartorius, N. (1999) The limits of mental health care in general medical services. In Common Mental Disorders in Primary Care (eds M. Tansella \& G. Thornicroft), pp. 2II221. London: Routledge.

Vázquez-Barquero, J. L., Herrera Castanedo, S., Artal, J. A., et al (1993) Pathways to psychiatric care in Cantabria. Acta Psychiatrica Scandinavica, 88, 229-234.

World Health Organization (1992) The ICD-10 Classification of Mental and Behavioral Disorders. Geneva: World Health Organization. 